\title{
岷江上游两种生态系统降雨分配的比较
}

\author{
李振新 ${ }^{1,2}$ 欧阳志云 ${ }^{1 *}$ 郑 华 $^{1}$ 刘兴良 $^{3}$ 宿以明 $^{3}$ \\ （1 中国科学院生态环境研究中心系统生态重点实验室 北京 100085) （2 东北师范大学环境科学系, 长春 130024) \\ (3 四川省林业科学研究院森林生态与环境资源研究所,成都 610081)
}

摘 要 植被的降雨分配作用对理解生态系统的水文功能具有重要的意义。该文对四川峎江上游峮江冷杉( Abies faxoniana) 针叶林和川滇高山栋( Quercus aquifolioides) 灌丛两种生态系统的降雨分配及降雨截留的影响因素进行了 研究 探讨了植被分配降雨及截留降雨的影响机制和影响因素。文中采用定位观测的方法研究降雨分配。针叶林 中冠层降雨截留占 $33.33 \%$ 树干茎流占 $0.07 \%$, 穿透雨占 $66.60 \%$; 而灌丛的冠层截留降雨为 $24.95 \%$,穿透雨为 $75.05 \%$, 针叶林地被物的蓄留水能力 $(1.746 \mathrm{~mm})$ 要大于灌丛地被物的持水能力 $(0.941 \mathrm{~mm})$, 针叶林土壤的容积含 水率 $(39.66 \%)$ 也要高于灌丛土壤的容积含水率 $(38.19 \%)$ 唡种生态系统中的穿透雨率与降雨量的关系均可用逻 辑斯谛方程较好地模拟。文中还选取了降雨量、降雨强度、降雨持续时间、两次降雨的间隔时间和次降雨期间的气 温等 5 种因子分析影响两种生态系统降雨截留的主要因素。根据截留降雨与上述 5 种因子的偏相关分析结果: 针 叶林冠层的降雨截留主要受降雨量、降雨持续时间和间隔时间的影响, 灌丛的降雨截留主要受降雨量、气温与降雨 持续时间的影响。文中从当地的降雨特征与两种生态系统微气候差异的角度分析了两种生态系统降雨分配及降 雨截留影响因素差异的原因。

关键词 降雨截留 降雨分配 峮江冷杉 高山栎灌丛 穿透雨 偏相关分析

\section{COMPARISON OF RAINFALL REDISTRIBUTION IN TWO ECOSYSTEMS IN MINJIANG UPPER CATCHMENTS , CHINA}

\author{
LI Zhen-Xin ${ }^{1}{ }^{2}$ OUYANG Zhi-Yun ${ }^{1 *}$ ZHENG Hua ${ }^{1}$ LIU Xing-Liang ${ }^{3}$ SU Yi-Ming ${ }^{3}$ \\ (1 Key Laboratory of Systems Ecology , Research Center for Eco-Environmental Sciences , Chinese Academy of Sciences , Beijing 100085 , China) \\ (2 Department of Environmental Sciences , Northeast Normal University, Changchun 130024 , China) \\ (3 Institute of Forest Ecology and Environmental Resources, Sichuan Academy of Forestry , Chengdu 610081, China)
}

\begin{abstract}
Background and Aims Ecosystems in western Sichuan Province are diverse , and their hydrological functions are important to the ecological stability of the upper drainages of the Yangtse River. It is important to study rainfall redistribution by vegetation in this area to understand the hydrological functions of ecosystems. We studied Abies faxoniana conifer forest and Quercus aquifolioides shrubland in the Dengsheng subalpine dark coniferous forests positioning research station in the upper catchments of Minjiang River, Sichuan. Our objectives were to :1) determine the magnitude of canopy layer interception, stem flow and water holding capability of ground litter and soil and 2) analyze factors that influence rainfall interception.
\end{abstract}

Methods We studied rainfall redistribution in the ecosystems from July to September , 2001 and June to August , 2002. We measured total rainfall with one standard and two automatic rain gages , throughfall with eight randomly placed barrel gages $(30 \mathrm{~cm}$ diameter and $40 \mathrm{~cm}$ height $)$ in the forest ecosystem and four in the shrub ecosystem, stem flow of trees in the forest ecosystem but not in the shrub ecosystem , and microclimate in both ecosystems and on open ground outside of the forest. Pearson correlation and partial correlation methods were used to analyze five factors influencing rainfall interception : rainfall volume, rainfall intensity , duration of single rainfall events , time interval between consecutive rainfall events and average air temperature during individual rainfall events.

Key Results In the forest ecosystem , canopy rainfall interception accounted for $33.33 \%$ of the total rainfall , stem flow $0.07 \%$ and throughfall $66.60 \%$. For the shrubland ecosystem, rainfall interception accounted for $24.95 \%$ and throughfall $75.05 \%$. Water holding capability was larger for conifer forest ground litter including 
lichens $(1.746 \mathrm{~mm})$ than for shrubland ground litter $(0.941 \mathrm{~mm})$. Bulk moisture content was larger for conifer forest $(39.66 \%)$ than shrubland $(38.19 \%)$. The relationship between throughfall percentage and rainfall could be modeled with a logistic equation .

Conclusions Interception in the conifer forest was mainly affected by rainfall volume, duration of rainfall and time interval time between consecutive rainfall events. For the shrubland, interception was mainly affected by rainfall volume, duration of rainfall and temperature. Differences between rainfall redistribution and factors affecting rainfall interception are analyzed and discussed in relation to local rainfall characteristics and microclimate differences between the two ecosystems.

Key words Interception, Rainfall redistribution, Abies faxoniana forest, Quercus aquifolioides shrubland, Throughfall , Partial correlation

植被对降雨的分配对区域的水文过程和水文功 能都具有重要的影响, 同时植被对降雨的分配对生 态系统的水分及养分循环具有重要的意义，因此关 于森林生态系统对降雨分配的研究一直是生态学和 生态水文学的研究热点。森林生态系统对降雨的分 配研究包括地上部分的降雨截留 (冠层截留和树干 蓄留)、地表的苔藓或/和枯枝落叶层的降雨蓄留以 及地下土壤层对降雨的蓄留等(刘世荣等,2003)。 在降雨分配的方面研究最多的是植被冠层对降雨的 截留作用, 降雨截留是影响植被蒸发散的一个重要 的水文过程。植被截留的降雨一般全部蒸发到大气 中, 因此可以看作是区域水平衡中的净损失部纷，还 有一些研究者认为半干旱区截留的降雨蒸发后又参 与到区域的降水循环中，因此不能看作是水分损失 (Gómez et al. 2001)。

四川西部具有十分多样的生态系统类型, 而且 其处于长江上游, 其生态系统的水文分配和水文功 能对于流域的生态稳定性及生态安全都有重要的影 响，因此对该区域森林生态系统的降雨截留及降雨 分配研究也是研究者关注的热点之一 (马雪华, 1987 谢春华等,2002; 巩合德等,2004; 李振新等, 2004 鲍文等,2004 ;巩合德等,2005)。但以前的研 究主要集中于森林生态系统的降雨分配, 对灌丛的 降雨分配研究较少, 而且对于影响森林冠层截留的 相关因素研究不多。

植被对降雨的分配及截留的机制是十分复杂 的。影响降雨截留的因素有植物叶片的大小、叶的 形状、质地、叶倾角、植被结构、风向、蒸发潜力 (温 度、空气湿度)等; 从降雨自身的影响看有降雨量和 降雨强度等 (Gómez et al。,2001; 陈引珍等,2005)。 不同地区、不同林型和不同的气候条件下, 植被降雨 的截留也有很大的变异(刘世荣等 2003)。

本研究在岷江上游的卧龙保护区内选择峮江冷
灌丛进行降雨分配的研究以及降雨截留影响因素的 研究, 目的是比较分析在同一研究地点不同生态系 统类型及不同微环境影响下两种生态系统降雨分配 的差异; 并且通过偏相关分析比较两种生态系统降 雨截留影响因素的异同, 以期更好地理解和解释植 被对降雨分配及降雨截留的机制, 并且为研究该区 域生态系统的水文调节功能提供基础数据。

\section{1 研究地点与方法}

\section{1 研究地点描述}

本研究在四川省卧龙自然保护区内进行, 选择 四川省林业科学研究院邓生亚高山暗针叶林定位站 (102 ${ }^{\circ} 58^{\prime} 21^{\prime \prime}$ E 30 $30^{\circ} 51^{\prime} 41^{\prime \prime} \mathrm{N}$; 海拔 $2805 \mathrm{~m}$ ) 附近的峮 江冷杉暗针叶林 (距定位站约 $500 \mathrm{~m}$, 阴坡; 海拔 $2810 \mathrm{~m}$ ) 和高山栎灌丛(距定位站约 $500 \mathrm{~m}$, 阳坡, 海 拔 $2835 \mathrm{~m}$ ) 研究两种生态系统的降雨分配作用, 两 种生态系统研究样地间相距不足 $1000 \mathrm{~m}$, 另外海拔 高度也基本一致，通过使用自计雨量计测量降雨，表 明两种生态系统样地间降雨量也基本一致。

卧龙自然保护区是我国面积最大的大熊猫自然 保护区之一。该区地处横断山脉东部的扔崃山系南 坡, 为四川盆地向川西高原过渡的地带。区内山高 谷深 相对高差悬殊, 达 $5100 \mathrm{~m}$ 。本区域属青藏高 原气候区，西风急流南支和东南季风控制着本区的 主要天气过程。邓生定位站位于卧龙自然保护区的 西南部, 邓生的气温以 12 月最低, 平均气温为 $-5.2{ }^{\circ} \mathrm{C}$, 以 7 月为最高, 平均为 $12.4{ }^{\circ} \mathrm{C}$, 年平均气 温为 $4.3{ }^{\circ} \mathrm{C}$, 年平均相对湿度约为 $79 \%$ 。年均降水 约 $848.9 \mathrm{~mm}$, 主要集中于 $6 \sim 9$ 月, 占全年降水的 $64.25 \%$ (约 $545.4 \mathrm{~mm}$ )。风向以北风及东北风为 主。年蒸发量为 $772.5 \mathrm{~mm}$,日照时数为 $1185.4 \mathrm{~h}$ 。

研究中选择的岷江冷杉林是卧龙地区中部及西 北侧分布最广, 蓄积量最大的针叶型森林。林下土 壤主要为发育于灰岩、千枚岩、玄武岩和砾状灰岩等 
基质的山地棕色暗针叶林土。在研究样地的调查中 (面积 $1012.3 \mathrm{~m}^{2}$ ), 岷江冷杉组成了针叶林乔木层 的主要树种, 此外乔木层还有红桦 (Betula albo-sinensis)、粘皮桦(B. utilis) 和川滇长尾械 (Acer caudatum var. prattii) 等树种, 林下植物主要有山光杜鹃 (Rhododendron oreodoxa) 、大叶金顶杜鹃 ( $R$. faberi subsp. pratti)、高山柳 (Salix dissa)、桦叶荚迷（Viburnum betulifolium) 和红毛花楸 (Sorbus rufopilosa) 等, 草 本层主要有华西箭竹 ( Fargesia nitida)。树冠层盖度 为 $70 \%$,群落总盖度约为 $75 \%$ 。胸径大于 $5 \mathrm{~cm}$ 的 树木密度为 839 株 $\mathrm{hm}^{-2}$,样方内树木 (胸径大于 5 $\mathrm{cm}$ ) 的平均胸径为 $20.02 \mathrm{~cm}$, 平均树高为 $12.37 \mathrm{~m}$, 平均枝下高为 $4.36 \mathrm{~m}$ 。地表有较为发达的苔藓层 (3 $5 \mathrm{~cm})$ 枯枝落叶层平均厚约 $3 \mathrm{~cm}$ 。研究中选择 的亚高山灌丛是卧龙地区较稳定的植物群落, 其组 成树种主要为川滇高山栎、高山柳和红花菩薇 ( Rosa moyesii)。林下草本不发达, 主要有光柄野青茅 (Deyeuxia henryi)、三角叶蟹甲草 (Cacalia deltophylla) 及少量苔草 (Carex spp.) 等。灌丛盖度约为 $80 \%$ ，灌 木高度平均为 $3.5 \mathrm{~m}$, 灌丛密度较大, 约为 7000 9000 株 $\mathrm{hm}^{-2}$ 。灌丛的树木枝干上有很多附生的叶 状地衣与毛木耳, 也有长松萝悬挂。地表无苔藓层 (因其植被高度较低, 且处于阳坡), 有枝状及叶状地 衣。枯枝落叶主要以川滇高山栎的落叶为主, 平均 厚度约为 $3 \mathrm{~cm}$ 。本研究开展的具体时间范围为 2001 年 $7 \sim 9$ 月以及 2002 年 $6 \sim 8$ 月。

\section{2 降雨分配的观测方法}

降雨观测:在针叶林研究样地和灌丛研究样地 附近的开阔地各设置了一个自计雨量计 (DSJ2 型, 天津气象仪器厂) 用以测量天然降雨 ( $R$ ), 并与约 $500 \mathrm{~m}$ 外的邓生定位站的 SM1 型标准雨量计做比 较。

穿透雨观测 :在岷江冷杉林样地中, 由于其植被 组成稍复杂 林冠覆盖度的空间变异较大, 因此在林 下采用系统与随机相结合的方法设置了 8 个直径为 $30 \mathrm{~cm}$ 的自制雨量筒（镀锌铁皮制做，圆雉形，上直 径 $\times$ 下直径 $\times$ 高为 $30 \mathrm{~cm} \times 25 \mathrm{~cm} \times 40 \mathrm{~cm}$ ) 用来测定 亚高山暗针叶林林下的穿透雨。灌丛的群落组成相 对简单, 植被覆盖度的空间变异较小, 在其林下随机 设置了 4 个自制雨量筒。雨量筒直接安放在林地地 面, 因为林地表面有较好的苔藓层和枯枝落叶层覆 盖, 因此不会有雨滴从外部溅入雨量筒内。每天 $8: 00 、 14: 00$ 和 $20: 00$ 分 3 个时间记录林下的各个点 的穿透雨量, 并计算出相应的穿透雨率。降雨的划
分按自计雨量计的记录, 将间隔时间超过 $4 \mathrm{~h}$ 的降 雨事件划分为两次不同的降雨事件。

树干茎流观测 :本研究中针叶林树干茎流的数 据采用定位站另一个针叶林研究样方中 6 个径级的 岷江冷杉树干茎流的测定数据。具体方法为在选定 的每株标准木上 采用剖开的胶皮管螺旋形地(绕 2 ３圈)围在刮平树皮的树干上做成截水槽，然后用 导管连通截水槽, 把茎流水引入地面上的集水器中 进行人工观测 获得标准树的单株茎流资料。然后, 将标准株茎流量按林木径阶及其权重进行统计,利 用加权平均法推算出单位面积林分的茎流量。而灌 丛因为其植株平均胸径很小,所以本研究中未测量 其树干茎流, 其降水分配只包括穿透水量与冠层截 留量。

枯枝落叶、苔藓层蓄留水分的调查 取样调查, 样方大小为 $0.5 \mathrm{~m} \times 0.5 \mathrm{~m}$, 调查时在针叶林及灌丛 中分别随机取 3 个样方用以调查针叶林下的苔藓、 枯枝落叶及灌丛林下的枯落物。将样方中的苔藓或 枯落物与土壤和石块仔细地分开, 并将样方内所有 的枯落物 (或枯落物 + 苔藓) 装入密封的塑料袋中, 带回实验室中立即称重, 测得其自然含水状态下的 重量。称重后, 将枯落物用水盆充分浸泡后(约 20 $\min )$ 取出放置于筛网上，等到枯落物没有水滴滴落 时再进行称重, 测得其最大含水状态下的重量。然 后将枯落物进行风干, 凤干至一定程度后(手感较干 燥)将其装入布袋中在烘箱中烘干，一般在 $80{ }^{\circ} \mathrm{C}$ 状 态下烘 16 20 h 可以干至恒重 (因枯落物量较多, 因此在烘干过程中需要检查和称重) ,烘干后立即称 重, 得到枯落物的干重。然后求出不同生态系统的 枯落物的自然含水率与最大含水率, 并计算出其蓄 水能力。

土壤水分的调查: 针叶林及灌丛的土壤均为山 地棕色暗针叶林土, 其土壤层厚度均约为 $100 \mathrm{~cm}$ 。 在两个样地内均随机取 3 个样点用环刀法分层取土 壤样品, 按 $0 \sim 20 、 20 \sim 40 、 40 \sim 60 \mathrm{~cm} 3$ 层取土壤样 品, 土壤样品密封于封口塑料袋中, 回实验室中立即 称重, 在 $110{ }^{\circ} \mathrm{C}$ 下烘干至恒重, 测定其土壤含水量, 并计算其容重和孔隙度。

\section{3 小气候观测}

在进行降雨截留观测及水土流失观测的同时， 实验中还对针叶林、灌丛以及林外的小气候进行了 观测，观测时间基本与降雨研究相同，按气象学的标 准方法进行观测。每天 8:00、14:00 和 20:00 分 3 次 进行观测, 主要观测气温、湿度、最高气温、最低气 
温、地表 $0 、 5 、 10 、 15$ 及 $20 \mathrm{~cm}$ 温度。小气候观测主要 是为了分析微气象条件的差异对于两种生态系统降 雨分配及林冠截留的影响。

\section{4 数据分析}

本研究中使用 SPSS10.0 软件进行逻辑斯谛方 程的模拟。在分析降雨截留与各种影响因素的关系 中使用了 SPSS10.0 软件中的 Pearson 相关分析和偏 相关分析地表枯落物咜量及吸水重以平均值 \pm 标 准差表示, 逻辑斯谛曲线图用 EXCEL 软件绘制。

\section{2 结果与分析}

\section{1 研究期间的降雨特征}

在进行观测研究的时间段内 (2001 年 7 9 月, 2002 年 $6 \sim 8$ 月) , 通过自计雨量计共记录降雨 56 次其中可用于针叶林下穿透雨研究的降雨为 35 次, 用于亚高山灌丛林下降雨分配研究的降雨为 26 次。对该区域的降雨实时记录表明，该区域的降雨 主要以中到小雨为主, 雨强普遍较小 (表 1), 雨强小 于 $1 \mathrm{~mm} \mathrm{~h}^{-1}$ 的小雨占记录降雨的 $71.4 \%$, 而雨强大 于 $5 \mathrm{~mm} \mathrm{~h}^{-1}$ 的降雨则只占观测降雨的 $1.8 \%$, 其余 为 $1 \sim 5 \mathrm{~mm} \mathrm{~h}^{-1}$ 的中级强度的降雨。从雨量分级来 看, 研究期间的降雨也基本以小雨和中雨为主, 其中 次降雨量小于 $5 \mathrm{~mm}$ 的降雨出现的频率为 $55.4 \%$, 次 降雨量为 5 15 mm 的降雨出现频率为 $33.9 \%$, 次降
雨量大于 $15 \mathrm{~mm}$ 的降雨占 $10.7 \%$ 。综上, 此地区的 降雨在 6 9 月期间较为频繁, 但降雨的强度及降雨 量均较小，降雨的侵蚀性也较小。

\section{2 邓生实验站针叶林、灌丛及林外小气候对比分} 析

在选取的时间段内的研究表明 (表 2), 针叶林 的气温平均较林外低 $0.5{ }^{\circ} \mathrm{C}$, 而灌丛由于其处于阳 坡, 而且植被高度较低, 因此气温与邓生定位站空地 的气温较接近, 仅较林外低 $0.1{ }^{\circ} \mathrm{C}$ 。相对湿度则以 针叶林内为最高, 灌丛次之, 林外最低。地温在研究 时间段内林外明显高于针叶林和灌丛相应的地温， 而灌丛的地温也平均比针叶林要高 $1{ }^{\circ} \mathrm{C}$ 左右。

\section{3 针叶林内降雨的分配格局}

针叶林内降雨的分配可以分为截留降雨、穿透 雨以及树干茎流。降落到地表的降水称为林内降雨 量, 其中一部分被苔藓和枯枝落叶层所截留, 一部分 产生临时的地表径流, 到达土壤表面的降雨经土壤 持留、渗透后一部分形成浅层壤中流, 还有一部分补 给地下水。

1) 穿透雨: 根据对 35 次降雨的穿透雨记录分 析，在实验期间岷江冷杉-大叶金顶杜鹃针叶林下的 总平均穿透雨率为 $66.60 \%$,其变化与降雨量的变 化关系可以用逻辑斯谛方程 (方程式 1) 较好地模拟 (图 1)。

表 12001 年 $7 \sim 9$ 月及 2002 年 $6 \sim 8$ 月邓生降雨特征

Table 1 The rainfall characteristics in Dengsheng from July to Sep. , 2001 and June to Aug. , 2002

\begin{tabular}{|c|c|c|c|c|c|c|}
\hline $\begin{array}{l}\text { 雨强分级 Classification of rainfall intensity } \\
\left(\mathrm{mm} \mathrm{h}^{-1}\right)\end{array}$ & $0 \sim 0.2$ & $0.2 \sim 0.5$ & $0.5 \sim 1.0$ & $1.0 \sim 2.0$ & $2.0 \sim 5.0$ & $>5.0$ \\
\hline 次数 Frequency & 10 & 18 & 12 & 10 & 5 & 1 \\
\hline 降雨量范围 Rrainfall range (mm) & $0.30 \sim 3.60$ & $0.70 \sim 9.00$ & $1.90 \sim 17.40$ & $0.60 \sim 25.50$ & $3.50 \sim 30.60$ & 6.10 \\
\hline 平均降雨量 Average rainfall $(\mathrm{mm})$ & 1.20 & 3.99 & 8.57 & 10.84 & 13.32 & 6.10 \\
\hline
\end{tabular}

表 2 林外、针叶林及灌丛的小气候比较

Table 2 Comparison of microclimate of conifer forest, shrub and open ground

\begin{tabular}{|c|c|c|c|c|c|c|c|c|c|}
\hline & $\begin{array}{c}\text { 气温 }\left({ }^{\circ} \mathrm{C}\right) \\
\text { Temperature }\end{array}$ & $\begin{array}{c}\text { 最低气温 } \\
\left({ }^{\circ} \mathrm{C}\right) \\
\text { Minimum } \\
\text { temperature } \\
\end{array}$ & $\begin{array}{c}\text { 最高气温 } \\
\left({ }^{\circ} \mathrm{C}\right) \\
\text { Maximum } \\
\text { temperature }\end{array}$ & $\begin{array}{c}\text { 相对湿度 } \\
(\%) \\
\text { Relative } \\
\text { humidity }\end{array}$ & $\begin{array}{c}0 \mathrm{~cm} \text { 地温 } \\
\left({ }^{\circ} \mathrm{C}\right) \\
0 \mathrm{~cm} \text { Soil } \\
\text { temperature }\end{array}$ & $\begin{array}{c}5 \mathrm{~cm} \text { 地温 } \\
\left({ }^{\circ} \mathrm{C}\right) \\
5 \mathrm{~cm} \text { Soil } \\
\text { temperature }\end{array}$ & $\begin{array}{c}10 \mathrm{~cm} \text { 地温 } \\
\left({ }^{\circ} \mathrm{C}\right) \\
10 \mathrm{~cm} \text { Soil } \\
\text { temperature }\end{array}$ & $\begin{array}{c}15 \mathrm{~cm} \text { 地温 } \\
\left({ }^{\circ} \mathrm{C}\right) \\
15 \mathrm{~cm} \text { Soil } \\
\text { temperature }\end{array}$ & $\begin{array}{c}20 \mathrm{~cm} \text { 地温 } \\
\left({ }^{\circ} \mathrm{C}\right) \\
20 \mathrm{~cm} \text { Soil } \\
\text { temperature }\end{array}$ \\
\hline $\begin{array}{l}\text { 林外 } \\
\text { Open ground }\end{array}$ & 12.9 & 6.0 & 25.5 & 77.9 & 16.5 & 15.4 & 15.2 & 14.8 & 14.7 \\
\hline $\begin{array}{l}\text { 针叶林 } \\
\text { Conifer forest }\end{array}$ & 12.4 & 6.0 & 22.0 & 83.8 & 12.4 & 11.4 & 11.0 & 10.8 & 10.7 \\
\hline $\begin{array}{l}\text { 灌丛 } \\
\text { Shrub }\end{array}$ & 12.8 & 6.0 & 28.0 & 79.7 & 13.3 & 12.0 & 11.7 & 11.8 & 11.8 \\
\hline
\end{tabular}




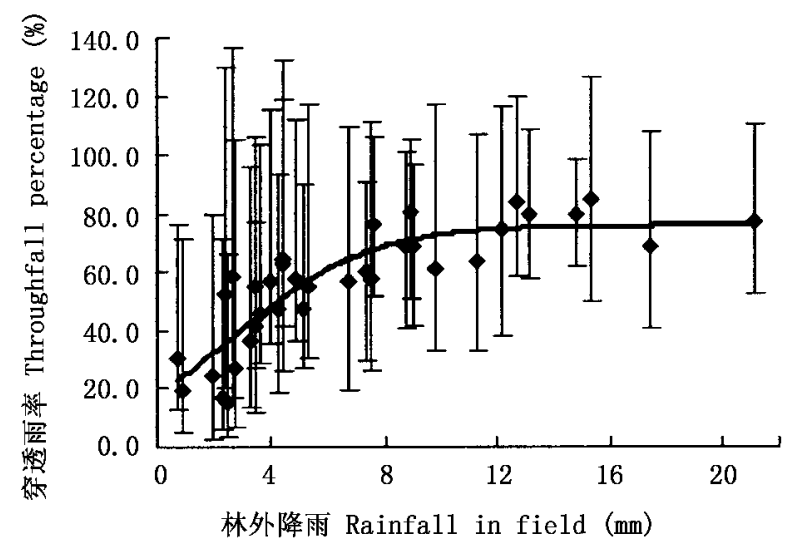

图 1 针叶林下穿透雨率与降雨量的关系及曲线拟合

Fig. 1 Scatterplot for throughfall percentage under conifer forest against rainfall and logistic fit

$T R=\frac{76.0739}{1+\mathrm{e}^{-0.4245(R-2.6674)}}$

式中：TR 代表穿透雨率 $(\%), R$ 代表林外降雨量 $(\mathrm{mm})$ 。公式 $(1)$ 的决定系数 $R^{2}=0.7523$ 。由此方程 式及图 1 可知, 在实验地点及当地的降雨条件下, 降 雨量达到 $10 \mathrm{~mm}$ 时其林下穿透雨率就接近其最大值 了。

2) 树干(茎)流:所有样树中观测到树干茎流的 最小次降雨量为 $1 \mathrm{~mm}$ ，一般次降雨量小于 $5 \mathrm{~mm}$ 时， 只有样树 1 产生了树干茎流，但如果观测降雨的上 一次降雨较大且与此次降雨的间隔时间较小时, 则 较小的降雨量也可能引起所有样树的树干茎流。同 时树干流有随岷江冷杉胸径增大而减少的现象。 本研究中对 2002 年 4 9 月期间岷江冷杉树干茎流 的分析表明, 峎江冷杉成熟林中平均树干径流在邓 生这样的降雨特征下仅占 $0.07 \%$,在林内降雨分配 的研究中几乎可以忽略不计。

3) 树冠层截留降雨: 树冠层截留降雨不能直 接测量, 只能通过以下公式计算出来：

$$
I=R-(T U+S)
$$

式中 : $I$ 代表冠层截留降雨量 $(\mathrm{mm}), R$ 代表林外降 雨量 $(\mathrm{mm}), T U$ 代表林下穿透雨 $(\mathrm{mm}), S$ 代表树干 茎流 $(\mathrm{mm})$ 。根据公式 (2)计算, 则冠层对降雨的截 留率为 $33.3 \%$, 同观测期间 $245.1 \mathrm{~mm}$ 的总降雨量相 比, 有 $81.6 \mathrm{~mm}$ 的降雨量被冠层截留。

\section{4 影响针叶林冠层截留雨量的因素分析}

树冠层截留的影响因素有: 降雨量、降雨强度、 降雨的持续时间、次降雨与上一次降雨的间隔时间、 降雨当日的气温、空气湿度以及风速等, 本研究中考
虑了前 5 种因素对针叶林树冠层降雨截留的影响, 因为没有测量林内及林地上空的风速, 而空气湿度 的同步记录不完整，所以没有考虑二者的影响。雨 量、雨强、降雨的持续时间以及降雨的间隔时间由自 计雨量记的记录得出, 距地面 $1.5 \mathrm{~m}$ 林内的气温由 湿度计每天 3 次记录 $(8: 00 、 14: 00$ 和 20:00) 平均得 出。因为两次降雨之间间隔的时间可能很长, 如果 以小时来计量降雨间隔时间, 由于变量之间的差值 太大 则不利于分析。研究中根据两次降雨间隔时 间对枝叶湿润度以及空气湿度的可能影响, 将其间 隔时间重新分类并赋与一个值, 这样重新转化的降 雨间隔时间有助于进行分析。具体分类方式如下： 间隔 $0 \sim 6 \mathrm{~h}$ (含 $6 \mathrm{~h}$ ) 的赋值 1 , 间隔 $6 \sim 12 \mathrm{~h}$ (含 $12 \mathrm{~h}$ ) 的赋值为 2 , 间隔 $12 \sim 24 \mathrm{~h}$ (含 $24 \mathrm{~h}$ ) 的赋值为 3 , 间 隔 $24 \sim 48 \mathrm{~h}$ (含 $48 \mathrm{~h}$ ) 的赋值为 4 , 间隔大于 $48 \mathrm{~h}$ 的 赋值为 5 ;共分为 5 级。

首先将树冠层截留雨量与上述 5 种因素分别进 行 Pearson 相关分析。由表 3 可知, 冠层截留与降雨 量和降雨持续时间有极显著相关, 与雨强、降雨的间 隔时间及温度无显著相关。但由于这 5 种因素之间 可能存在一定的相互影响, 因此进行偏相关分析更 能说明这 5 种因素的真实影响。结果表明:冠层截 留与降雨量之间的相关度极显著, 相关系数为 0.591 $(p<0.001)$; 其次为降雨的持续时间, 相关系数为 $0.392(p=0.029)$; 与降雨的间隔时间的相关系数为 $0.383(p=0.033)$ 。截留量与林内气温以及降雨强 度无显著相关。

在偏相关分析的基础上，以树冠截留量作为因 变量, 以降雨量、降雨持续时间及间隔时间等 3 个因 子作为自变量作多元回归, 得到方程如下：

$$
I=0.167+0.151 R+0.035 D A+0.259 I N T
$$

式中 : $I$ 代表冠层截留雨量 $(\mathrm{mm}), R$ 代表降雨量 $(\mathrm{mm}), D A$ 代表次降雨的持续时间 ( h ) , INT 代表两 次降雨的间隔时间（重新赋值后无量纲）,此方程的 相关系数为 $0.861(p<0.001)$, 可见以降雨量、降雨 持续时间与间隔时间这 3 个因子可以在研究地点对 岷江冷杉林的树冠截留进行很好的线性模拟。

\section{5 川滇高山栎灌丛的降雨分配}

本研究中共记录川滇高山栎冠层下有效穿透雨 共 26 次 时间段与针叶林相同。研究亚高山灌丛的 降雨分配只观测了其林下穿透雨, 因为灌丛的树干 其胸径一般均较小，因此对其树干流未做观测记录， 研究中这部分忽略不计。 
表 3 针叶林树冠截留与其它因素的 Pearson 相关及偏相关系数

Table 3 The Pearson correlation and the partial correlation coefficients of rainfall intercepion and other influencing factors of conifer forest

\begin{tabular}{|c|c|c|c|c|c|c|}
\hline \multirow[t]{2}{*}{$\begin{array}{l}\text { Pearson 相关分析 } \\
\text { Pearson correlation }\end{array}$} & \multirow{2}{*}{$\begin{array}{l}\text { 冠层截留 } \\
\text { Interception of } \\
\text { rainfall by } \\
\text { canopy }(I)\end{array}$} & $\begin{array}{c}\text { 降雨量 } \\
\text { Rainfall } \\
(R)\end{array}$ & $\begin{array}{c}\text { 雨强 } \\
\text { Rainfall } \\
\text { intensity }(R I)\end{array}$ & $\begin{array}{c}\text { 持续时间 } \\
\text { Duration of } \\
\text { the rainfall } \\
\quad(D A)\end{array}$ & $\begin{array}{c}\text { 间隔时间 } \\
\text { Interval time } \\
\text { of two rainfall } \\
\quad(I N T)\end{array}$ & $\begin{array}{c}\text { 温度 } \\
\text { Temperature } \\
(T)\end{array}$ \\
\hline & & $\begin{array}{c}0.794 \\
p<0.001\end{array}$ & $\begin{array}{c}0.249 \\
p=0.150\end{array}$ & $\begin{array}{c}0.558 \\
p<0.001\end{array}$ & $\begin{array}{c}0.133 \\
p=0.445\end{array}$ & $\begin{array}{c}-0.035 \\
p=0.840\end{array}$ \\
\hline \multirow{2}{*}{$\begin{array}{c}\text { 偏相关分析 } \\
\text { Partial correlation }\end{array}$} & \multirow[b]{2}{*}{$I$} & $R$ & $R I$ & $D A$ & INT & $T$ \\
\hline & & $\begin{array}{c}0.591 \\
p<0.001\end{array}$ & $\begin{array}{c}0.202 \\
p=0.277\end{array}$ & $\begin{array}{c}0.392 \\
p=0.029\end{array}$ & $\begin{array}{c}0.383 \\
p=0.033\end{array}$ & $\begin{array}{c}-0.063 \\
p=0.736\end{array}$ \\
\hline
\end{tabular}

观测期间在总降雨量为 $241.1 \mathrm{~mm}$ 的情况下, 有 $75.05 \%$ 的降雨形成穿透雨, 若忽略其树干茎流, 则 有约 $24.95 \%$ 的降雨被灌丛冠层截留, 即共有约 $60.15 \mathrm{~mm}$ 的降雨被冠层截留。

灌丛林下的穿透雨率与林外降雨量的关系也可 以用逻辑斯谛方程进行比较好的模拟,具体方程式 如下:

$$
T R=\frac{75.9197}{1+\mathrm{e}^{-0.9342(R-0.6858)}}
$$

式中 : $T R$ 为穿透雨率 $(\%), R$ 为林外降雨量 $(\mathrm{mm})$, 公式(4)的决定系数 $R^{2}=0.4033$ 。在观测期间的降 雨条件下, 降雨量约 $7 \mathrm{~mm}$ 时，林下的穿透雨率就接 近了最大穿透雨率 (图 2), 这说明灌丛林冠的截留 降雨量要小于针叶林冠的截留降雨量。

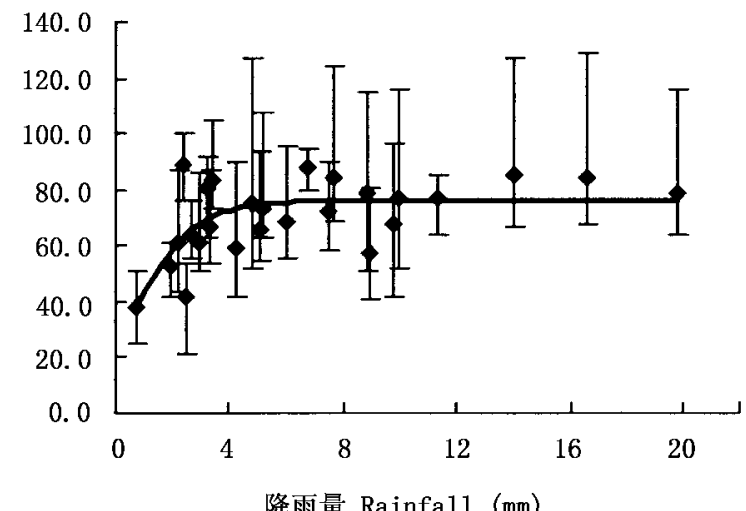

图 2 亚高山灌丛林下的穿透雨率与降雨量的关系及曲线拟合

Fig.2 Scatterplot for throughfall percentage under subalpine shrub against rainfall and logistic fit

\section{6 影响灌丛林冠层截留雨量的因素分析}

对灌丛截留雨量的影响因素选择与影响针叶林 冠层截留雨量的因素一致，对降雨间隔时间的重新 分级与针叶林部分相同。

树冠层截留雨量与上述 5 种因素分别进行 Pearson 相关分析 (表 4) ,冠层截留与降雨量和降雨
持续时间有极显著相关, 与林内的气温有显著负相 关,与雨强及降雨的间隔时间无相关关系。偏相关 分析结果表明 :冠层截留与降雨量之间的相关性极 显著 相关系数为 $0.679(p<0.001)$; 其次为降雨当 日林内的气温 相关系数为 $-0.520(p=0.013)$;与 降雨持续时间的相关系数为 $0.445(p=0.038)$; 与 降雨的间隔时间以及降雨强度无显著相关。

在偏相关分析的基础上，以树冠截留量作为因 变量, 以降雨量、降雨当天林内的气温和降雨持续时 间 3 个因子作为自变量作多元回归, 得到方程如下：

$$
I=2.307+0.131 R+0.039 D A-0.173 T
$$

式中 :各参数含义同公式 $(3), T$ 代表灌丛林下地表 $1.2 \mathrm{~m}$ 处气温 $\left({ }^{\circ} \mathrm{C}\right)$, 方程式的相关系数为 $0.902(p$ $<0.001)$, 可见以降雨量、降雨时林内的气温和降雨 持续时间这 3 个因子可以在研究地点对亚高山灌丛 的树冠层截留进行很好的线性模拟。

\section{7 地表苔藓及枯落物层蓄留水分的潜力}

针叶林的枯落物层主要是岷江冷杉的针叶和一 些细的枯枝, 此外还有少量的未分解的阔叶; 灌丛地 表枯落物主要为川滇高山柇的落叶和枯枝。针叶林 的苔藓层、枯落物层以及灌丛的枯落物层均有较好 的蓄水能力 (表 5 ), 单位重量苔藓层的蓄水潜力最 大, 灌丛枯落物的蓄水潜力也大于针叶林。经计算 针叶林的地被物在一次降雨中最大的蓄水潜力为 $1.746 \mathrm{~mm}\left(17464 \mathrm{~kg} \mathrm{hm}^{-2}\right)$, 灌丛地被物的蓄水潜 力为 $0.941 \mathrm{~mm}\left(9406 \mathrm{~kg} \mathrm{hm}^{-2}\right.$, 灌丛地被物中没有 苔藓层), 针叶林地被物的蓄水潜力约为灌丛蓄水潜 力的 1 倍。

\section{8 两种生态系统土壤的蓄水潜力}

两种生态系统的土壤容重存在显著差异, 针叶 林土壤的 $0 \sim 60 \mathrm{~cm}$ 的平均土壤容重为 $0.741 \mathrm{~g}$ $\mathrm{cm}^{-3}$, 平均土壤孔隙度高达 $72.04 \%$ ，土壤容积含水 量为 $39.66 \%$; 而灌丛相应的土壤容重、孔隙度、容 积含水量分别为 $0.873 \mathrm{~g} \mathrm{~cm} \mathrm{~cm}^{-3} 、 67.06 \% 、 38.19 \%$ 
(表 6 )。在研究期间, 两种生态系统的土壤容积含 水量均较高, 但在各层次中的分配有一定的差异, 针
叶林表层含水量较大, 而灌丛的含水量则出现了相 反的趋势(表 6)。

表 4 亚高山灌丛树冠截留与其它因素的 Pearson 相关及偏相关系数

Table 4 The Pearson correlation and the partial correlation coefficients of rainfall intercepion and other influencing factors of subalpine shrub

\begin{tabular}{|c|c|c|c|c|c|c|}
\hline \multirow[t]{2}{*}{$\begin{array}{l}\text { Pearson 相关分析 } \\
\text { Pearson correlation }\end{array}$} & \multirow{2}{*}{$\begin{array}{l}\text { 冠层截留 } \\
\text { Interception of } \\
\text { rainfall by } \\
\text { canopy }(I)\end{array}$} & $\begin{array}{c}\text { 降雨量 } \\
\text { Rainfall } \\
(R)\end{array}$ & $\begin{array}{c}\text { 雨强 } \\
\text { Rainfall } \\
\text { intensity }(R I)\end{array}$ & $\begin{array}{l}\text { 持续时间 } \\
\text { Duration of } \\
\text { the rainfall } \\
(D A)\end{array}$ & $\begin{array}{c}\text { 间隔时间 } \\
\text { Interval time } \\
\text { of two rainfall } \\
(I N T)\end{array}$ & $\begin{array}{c}\text { 温度 } \\
\text { Temperature } \\
(T)\end{array}$ \\
\hline & & $\begin{array}{c}0.818 \\
p<0.001\end{array}$ & $\begin{array}{c}-0.014 \\
p=0.947\end{array}$ & $\begin{array}{c}0.690 \\
p<0.001\end{array}$ & $\begin{array}{c}0.076 \\
p=0.712\end{array}$ & $\begin{array}{c}-0.468 \\
p=0.016\end{array}$ \\
\hline \multirow{2}{*}{$\begin{array}{c}\text { 偏相关分析 } \\
\text { Partial correlation }\end{array}$} & \multirow[b]{2}{*}{$I$} & $R$ & $R I$ & $D A$ & $I N T$ & $T$ \\
\hline & & $\begin{array}{c}0.684 \\
p<0.001\end{array}$ & $\begin{array}{c}0.091 \\
p=0.688\end{array}$ & $\begin{array}{c}0.445 \\
p=0.038\end{array}$ & $\begin{array}{c}0.177 \\
p=0.432\end{array}$ & $\begin{array}{c}-0.520 \\
p=0.013\end{array}$ \\
\hline
\end{tabular}

表 5 苔藓及枯落物的咜量及吸持水状况

Table 5 The stocking weight of lichen and ground litter, and theirs water storage capacity

\begin{tabular}{|c|c|c|c|c|c|c|c|}
\hline $\begin{array}{l}\text { 类型 } \\
\text { Type }\end{array}$ & $\begin{array}{c}\text { 厚度 } \\
\text { Thick }(\mathrm{cm})\end{array}$ & $\begin{array}{c}\text { 地表盖度 } \\
\text { Coverage }\end{array}$ & $\begin{array}{c}\text { 干重 } \\
\text { Dry weight } \\
\left(\mathrm{g} \mathrm{m}^{-2}\right) \\
\text { (平均值 } \pm \text { 标准差 }) \\
(\text { Mean } \pm S D)\end{array}$ & $\begin{array}{c}\text { 原重 } \\
\text { Natural weight } \\
\left(\mathrm{g} \mathrm{m}^{-2}\right) \\
\text { (平均值 } \pm \text { 标准差) } \\
\text { Mean } \pm S D)\end{array}$ & $\begin{array}{c}\text { 最大吸水重 } \\
\text { Weight with maximum } \\
\text { water storage } \\
\left(\mathrm{g} \mathrm{m}^{-2}\right) \\
\text { (平均值 } \pm \text { 标准差) } \\
\text { Mean } \pm S D)\end{array}$ & $\begin{array}{c}\text { 自然吸水率 } \\
\text { Natural water } \\
\text { storage } \\
\text { capacity }(\%)\end{array}$ & $\begin{array}{c}\text { 最大吸水率 } \\
\text { Maximum water } \\
\text { storage } \\
\text { capacity }(\%)\end{array}$ \\
\hline $\begin{array}{c}\text { 苔藓 } \\
\text { Lichen (3) }\end{array}$ & 4 & $60 \%$ & $175.3 \pm 65.6$ & $660.7 \pm 322.3$ & $1110.1 \pm 528.7$ & $368.3 \%$ & $620.4 \%$ \\
\hline $\begin{array}{c}\text { 针叶林枯落物 } \\
\text { Ground litter in } \\
\text { conifer forest (3) }\end{array}$ & 3 & $90 \%$ & $2199.8 \pm 459.4$ & $6760.0 \pm 1951.6$ & $8065.5 \pm 2199.6$ & $307.3 \%$ & $366.6 \%$ \\
\hline $\begin{array}{c}\text { 灌丛枯落物 } \\
\text { Ground litter in shrub (3) }\end{array}$ & 3 & $95 \%$ & $895.8 \pm 125.5$ & $2533.3 \pm 334.9$ & $3468.1 \pm 433.8$ & $283.0 \%$ & $388.0 \%$ \\
\hline
\end{tabular}

第一列括号后的数字为调查样方数 The number in bracket of the first row is the sample number

表 6 两种生态系统的土壤容重及土壤含水量

Table 6 The bulk density of soil and soil moisture content of the two ecosystems

\begin{tabular}{|c|c|c|c|c|c|c|}
\hline \multirow{3}{*}{$\begin{array}{c}\text { 层次 } \\
\text { Soil layer }(\mathrm{cm})\end{array}$} & \multicolumn{2}{|c|}{$\begin{array}{c}\text { 土壤容重 } \\
\text { Bulk density of sil }\left(\mathrm{g} \mathrm{cm}^{-3}\right)\end{array}$} & \multicolumn{2}{|c|}{$\begin{array}{c}\text { 土壤孔隙度 } \\
\text { Soil porosity }(\%)\end{array}$} & \multicolumn{2}{|c|}{$\begin{array}{c}\text { 土壤容积含水量 } \\
\text { Bulk moisture content of soil }(\%)\end{array}$} \\
\hline & 针叶林 & 灌丛 & 针叶林 & 灌丛 & 针叶林 & 灌丛 \\
\hline & Conifer forest & Shrub & Conifer forest & Shrub & Conifer forest & Shrub \\
\hline $0 \sim 20$ & 0.652 & 0.731 & 75.40 & 72.42 & 41.00 & 34.55 \\
\hline $20 \sim 40$ & 0.792 & 0.894 & 70.11 & 66.26 & 43.54 & 37.63 \\
\hline $40 \sim 60$ & 0.779 & 0.993 & 70.60 & 62.53 & 34.45 & 42.40 \\
\hline 平均 Average & 0.741 & 0.873 & 72.04 & 67.06 & 39.66 & 38.19 \\
\hline
\end{tabular}

\section{9 两种生态系统降雨分配的比较}

对两种生态系统对降雨的截留及削减作用进行 比较可以看出 岷江冷杉林具有较高降雨截留作用 (截留率约 $33.3 \%$ )，虽然其覆盖度略低于川滇高山 栎灌丛, 但由于其冠层高度较高, 其枝叶层的厚度要 远远大于灌丛的枝叶层厚度, 其叶面积指数也大于 后者, 因此其冠层截留降雨的能力比灌丛(截留率约 $24.95 \%$ ) 高出很多; 怅江冷杉林地表的苔藓及枯落
物层的截留降雨潜力大于川滇高山栎灌丛地表枯落 物的截留降雨潜力; 另外针叶林土壤的蓄水潜力稍 大于灌丛土壤的蓄水潜力。

\section{3 讨 论}

\section{1 两种生态系统降雨分配的差异}

本研究中亚高山暗针叶林和灌丛的冠层截留率 均较高, 针叶林的冠层截留率达 $33.33 \%$ 。马雪华 
(1987) 在四川米亚罗地区研究藓类冷杉林的降雨截 留, 得出 5 10 月间其林冠层截留率为 $26.7 \%$; 而黄 礼隆 (1994)在研究四川西部亚高山暗针叶林的降雨 截留时得出其截留率为 $32.42 \%$, 与本研究中得到 的结果十分接近。在卧龙邓生的怅江冷杉林进行降 雨分配研究时, 研究者发现很多降雨到达林冠层后 会形成明显的雾气, 这可能是由于雨滴与林冠撞击 以及林冠表面热量急剧变化等原因造成的, 这些雾 气沿山坡向坡上方飘动, 这部分雾气带走的水分可 能也会降低林下穿透雨的计量, 因此会导致树冠截 留被高估。而对于阳坡的川滇高山栎灌丛也有类似 的现象, 但这种现象出现的频率低于针叶林。

本文中用逻辑斯谛方程模拟两种生态系统林下 的穿透雨率与降雨量的关系, 这与其它研究者常用 的数学模型有一定的差异, 关于此模型的使用在研 究者的另一篇文章中进行过详细的讨论(李振新等, 2004)。

\section{2 岷江冷杉林的树干茎流}

岷江冷杉林的树干茎流随树干胸径的增加有减 少的趋势, 这主要与其树种的生长特点有关, 当其为 幼树时, 树皮较光滑, 并且树枝等也较光滑; 而岷江 冷杉长至中龄以后其树皮表面出现裂纹, 并随树龄 的增长而加深, 另外树木的高度也增加了, 分枝的表 面也变得粗粘, 而且树枝上附着的较多的 松夢” 也 减少了枝叶层的截留水分沿枝条汇聚到树干的量。

王景升等 (2002) 在研究西藏的急尖长苞冷杉 (Abies georgei var. smithii)的降水分配格局时发现其 干流量与树干直径、冠幅和树皮厚度呈负相关关系， 即随着林木胸径的增加、林冠覆盖面积增大和树皮 增厚而干流量减小。长苞冷杉的干流量仅占林外同 期降雨量的 $0.80 \%$ 。其研究结果与本研究比较一 致。而在印度尼西亚热带雨中的研究则表明, 树干 流有随树木基部面积的增加而增大的趋势 (Asdak et al. , 1998)。

\section{3 影响降雨截留的因素}

本研究中采用了多元线性回归来模拟冠层的截 留雨量, 目的主要是为了分析其它因素对降雨截留 的影响，而且这是适合于观测期间的雨强及雨量的。 因为冠层存在着一个饱和截留量, 不可能随着降雨 量的增加而呈线性无限增加。一般研究者都用幂函 数方程式来模拟截留雨量与降雨量之间的关系, 取 得了较好的结果(谢春华等, 2002; 王鸣远和王礼先， 1995)。

影响降雨截留的因素有植被冠层的枝叶密度或
叶面积指数、枝叶的质地和形状、枝叶的伸展状态、 降雨前期的枝叶干燥程度、气温、降雨量、降雨的强 度与持续时间、风速和风向等。本研究中主要对比 了针叶林和灌丛的降雨截留, 针叶林的降雨截留显 著大于灌丛, 这可能主要与针叶林具有较高的叶面 积指数有关。另外对两种生态系统的林冠层降雨截 留的影响因素分析了降雨量、雨强、降雨的持续时 间、间隔时间与降雨当日平均气温对其的影响，结果 针叶林冠层降雨截留主要受降雨量、持续时间和间 隔时间的影响, 而灌丛的冠层截留主要受降雨量、降 雨当日的气温与持续时间的影响，与降雨的间隔时 间及雨强无线性相关。这可能是由于亚高山灌丛处 于阳坡, 而且灌丛的群落高度较低, 一次降雨过后, 灌丛的林冠层的枝叶很容易在短时间内干燥, 因此 既使降雨间隔时间再长, 其冠层的干燥度差别也不 大。而针叶林处于阴坡, 其群落高度也较高, 冠层截 留的降雨蒸发所需时间较长, 因此降雨间隔时间的 长短对其冠层整体的干燥度影响较大, 对这个因素 的变化也有较好的相关关系。在两种生态系统的降 雨截留中, 截留降雨均与降雨当日的温度呈一定的 负相关，而对灌丛这种负相关达到了显著水平，这主 要与当地气温受降雨影响较大有关, 尤其是处于阳 坡的灌丛温差变化要大于阴坡的针叶林。本论文的 研究结果与陈引珍等 (2005)的研究结果有一定的差 异、陈引珍等 (2005) 对缙云山区影响林冠截留量因 素进行了灰色关联度分析, 认为对降雨截留的主要 因素为降雨量、降雨强度、气温、风速和空气湿度等， 对针阔混交林、阔叶林和毛竹林不同的影响因素其 影响大小也有差别。

本研究中降雨强度对针叶林和灌丛的林冠截留 均没有显著的影响, 这与其它学者的研究结果有一 定的差异, Llorens 等 (1997) 研究地中海山地森林的 降雨截留时发现, 降雨强度是影响降雨截留的主要 因素, 而降雨的持续时间对降雨截留则没有什么影 响。造成这种差异的一个重要原因可能是两个地区 的降雨特征不同, 卧龙保护区内的降雨主要是以中 到小雨为主, 很少出现暴雨, 因此其雨强变化程度也 较小, 体现不出雨强对截留的影响。而降雨的持续 时间一般较长, 因此在降雨过程中的蒸发可能会增 加冠层的截留量。

Klaassen 等(1996) 通过模拟和实测相对比的研 究方法研究了树冠边缘蒸发与截留的特点, 其模拟 研究认为在上风向树冠边缘的冠层其蒸发速率明显 增大, 这样就可能导致上风向树冠边缘处的降雨截 
留量比较大 相应的其林下穿透雨量会减少; 但是其 随后进行的实测研究却没有反映出这种趋势。这可 能是因为穿透雨更主要地不是受其上林冠的蒸发率 所控制，可能与树形、枝叶伸展状态等有更密切的关 系。

此外还有一些研究者研究了风向对穿透雨或截 留降雨的影响,Gómez 等(2002)研究了橄榄(Olea europaea ) 树下的穿透雨率与研究地的主导风向之间的 关系，虽然从表面上看在东风及东南风向时林下的 穿透雨率大于西南风及西风向，但由于前两种风向 下的降雨量明显大于后者, 因此不能断定风向与林 下的穿透雨率之间存在的影响。

\section{参 考 文 献}

Asdak C, Jarvis PG, van Gardingen P, Fraser A (1998). Rainfall interception loss in unlogged and logged forest areas of central Kalimantan, Indonesia. Journal of Hydrology, 206, 237 - 244. Bao W (鲍文), Bao WK (包维楷), He BH (何柄辉), Ding DR (丁德蓉) (2004). Redistribution effects of tree canopy of the artificial Pinus tabulaeformis forest on precipitation in the upperstream of Minjiang River. Journal of Beijing Forestry University (北京林业大学学报), 26(5), 10-16. (in Chinese with English abstract)

Chen YZ (陈引珍), He F (何凡), Zhang HJ (张洪江), Wen XS (温熙胜) (2005). Preliminary analysis on factors influencing canopy interception in Jinyun Mountain. Science of Soil and Water Conservation (中国水土保持科学), 3(3), 69-72. (in Chinese with English abstract)

Gómez JA, Giráldez JV, Fereres E (2001). Rainfall interception by olive trees in relation to leaf area. Agricultural Water Management, 49, 65-76.

Gómez JA, Vanderlinden K, Giráldez JV, Fereres E (2002). Rainfall concentration under olive trees. Agricultural Water Management, 55, $53-70$.

Gong HD (巩合德), Wang KY (王开运), Yang WQ (杨万勤), Wang Q (王乾), Zhang YB (张远涁) (2004). Throughfall and stemflow in a Betula platyphylla forest at the subalpine of western Sichuan. Chinese Journal of Ecology (生态学杂志), 23(4), 17 - 20. (in Chinese with English abstract)

Gong HD (巩合德), Wang KY (王开运), Yang WQ (杨万勤), Wang Q (王乾), Zhang YB (张远涁) (2005). Throughfall and stemflow in a primary spruce forest in the subalpine of west- ern Sichuan. Scientia Silvae Sinicae (林业科学), 41, 198 201. (in Chinese with English abstract)

Huang LL (黄礼隆) (1994). Pimary study on water conservation function of subalpine forest in western Sichuan. In: Zhou XF (周 晓峰) ed. Long-Term Studies of Forest Ecosystems in China (中 国森林生态系统定位研究). Northeast Forestry University Press, Harbin, 400-412. (in Chinese with English abstract)

Klaassen WH, Landreijer JM, Veen AWL (1996) . Rainfall interception near a forest edge. Journal of Hydrology, 185, 349 361 .

Li ZX (李振新), Zheng H (郑华), Ouyang ZY (欧阳志云), Wang XK (王效科), Liu XL (刘兴良), Su YM (宿以明) (2004). The spatial distribution characteristics of throughfall under Abies faxoniana forest in the Wolong Nature Reserve. Acta Ecologica Sinica (生态学报), 25, 1015 - 1021. (in Chinese with English abstract)

Liu SR (刘世荣), Sun PS (孙鹏森), Wen YG (温远光) (2003) . Comparative analysis of hydrological functions of major forest ecosystems in China. Acta Phytoecologica Sinica (植物生 态学报), 27, 16-22. (in Chinese with English abstract)

Llorens PR, Poch J, Latron J, Gallart F (1997) . Rainfall interception by a Pinus sylvestris forest patch overgrown in a Mediterranean mountainous abandoned area. I. Monitoring design and results down to the event scale. Journal of Hydrology, 199, 331 -345 .

Ma XH (马雪华) (1987). Studies on hydrological function of alpine fir in Miyaluo, Sichuan Province. Scientia Silvae Sinicae (林业科学), 23, $253-265$. (in Chinese with English abstract)

Wang JS (王景升), Ren QS (任青山), Lan XZ (兰小中) (2002). Study on the distribution pattern of precipitation in Abies georgei var. smithii virgin forest. Forestry Science \& Technology (林业科技), 27(6), 7-10. (in Chinese with English abstract)

Wang MY (王鸣远), Wang LX (王礼先) (1995). Effect of masson pine forests on rainfall interception in the reservoir area of the Three Gorges of Yangtze River. Journal of Beijing Forestry University (北京林业大学学报), 17(4), 74-81. (in Chinese with English abstract)

Xie CH (谢春华), Guan WB (关文彬), Wu JA (吴建安), Cheng GW (程根伟), Luo J (罗辑) (2002). Interception capability of dark coniferous forest ecosystem in Gongga Mountain. Journal of Beijing Forestry University (北京林业大学学报), 24(4), 68-71. (in Chinese with English abstract) 